\title{
宷 \\ ONDE E QUANDO CULTURA QUER DIZER LIBERDADE E CRIATIVIDADE
}

\section{- PAULO CESAR DA COSTA GOMES ${ }^{1}$}

Professor Titular do Departamento de Geografia da Universidade Federal do Rio de Janeiro (UFRJ). E-mail: pccgomes@yahoo.com.br

Recebido em: 10/11/2020

Aprovado em: $23 / 11 / 2020$

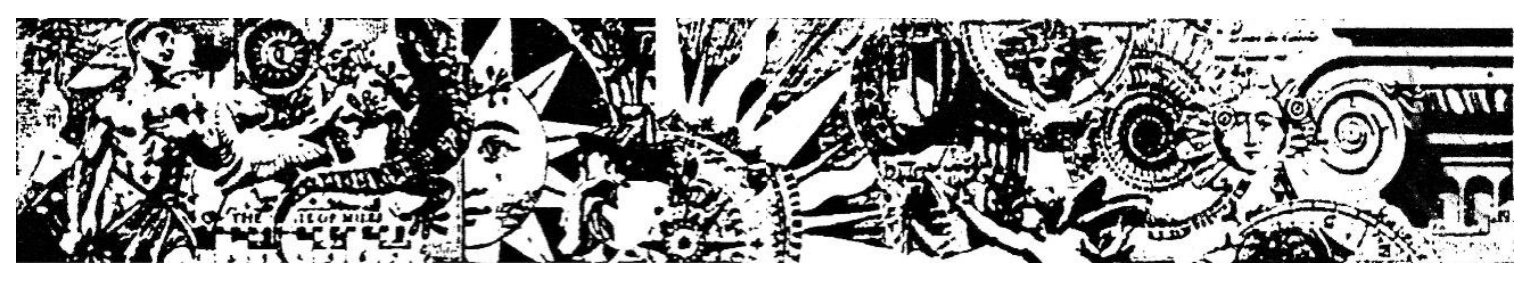

Resumo: $O$ artigo demonstra como os sucessivos Simpósios sobre Espaço e Cultura, organizados pelo NEPEC, assim como a revista Espaço e Cultura, consolidaram um espaço de liberdade temática e teóricometodológica na Geografia brasileira. Para isso o autor comenta três de suas contribuições apresentadas nesses eventos.

Palavras-chave: Geografia Cultural; Sociologia da ciência; NEPEC.

\section{WHERE AND WHEN CULTURE MEANS FREEDOM AND CREATIVITY}

ABSTRACT: THE ARTICLE DEMONSTRATES HOW THE SUCCESSIVE SYMPOSIUMS ON SPACE AND CULTURE, ORGANIZED BY NEPEC, AS WELL AS THE ESPAÇO E CULTURA REVIEW, CONSOLIDATED A THEMATIC, THEORETICAL AND METHODOLOGICAL SPACE OF FREEDOM IN BRAZILIAN GEOGRAPHY. TO DEMONSTRATE THIS, THE AUTHOR COMMENTS ON THREE OF HIS CONTRIBUTIONS PRESENTED AT THESE EVENTS.

KEYWORDS: CULTURAL GEOGRAPHY; SOCIOLOGY OF SCIENCE; NEPEC. 


\title{
DÓNDE Y CUÁNDO CULTURA SIGNIFICA LIBERTAD Y CREATIVIDAD
}

\begin{abstract}
RESUMEN: EL ARTÍCULO DEMUESTRA CÓMO LOS SUCESIVOS SIMPOSIOS SOBRE ESPACIO Y CULTURA, ORGANIZADOS POR NEPEC, ASÍ COMO LA REVISTA ESPAÇO E CULTURA, CONSOLIDARON UN ESPACIO DE LIBERTAD TEMÁTICA Y TEÓRICO-METODOLÓGICA EN LA GEOGRAFÍA BRASILEÑA. PARA DEMOSTRARLO, EL AUTOR COMENTA TRES DE SUS APORTACIONES PRESENTADAS EN ESTOS EVENTOS Y POSTERIORMENTE PUBLICADAS.
\end{abstract}

PALABRAS CLAVE: GEOGRAFÍA CULTURAL; SOCIOLOGÍA DE LA CIENCIA; NEPEC.

$\mathrm{O}$ homem de bem se entende com os outros, sem necessariamente fazer como eles. $\mathrm{O}$ homem comum faz como os outros, sem necessariamente se entender com eles. Princípio do confucionismo da harmonia sem uniformidade (he er bu tong).

Há um manifesto desinteresse dos geógrafos por pesquisas no campo da sociologia da ciência. Inexplicavelmente, pouquíssimos trabalhos se dedicam a reconhecer o papel das circunstâncias sociais e institucionais como um elemento central na compreensão dos rumos da disciplina. No Brasil não conheço nenhum exemplo notório. Afora algumas tímidas tentativas sem posteridade, como a de Monteiro (1988), quase nada foi produzido como material de reflexão nessa área. $\mathrm{O}$ tema aparece de maneira secundária em alguns trabalhos de história da geografia, mas o tratamento está sempre submetido a uma razão cronológica simplista e empobrecida - post hoc ergo propter hoc. ${ }^{1}$ Falta aquilo que a noção de sociologia acrescenta à história da ciência, ou seja, uma análise fina do contexto, dos sistemas, instrumentos e estruturas de legitimidade, notoriedade e prestígio que, desde o pioneiro trabalhos de Kuhn, deveriam nos manter atentos para as condições particulares nas quais os temas de uma determinada área de conhecimento são escolhidos, tratados e aceitos, as instâncias que garantem reconhecimento e os diferentes personagens que participam desse complexo sistema.

Se a constatação da ausência dessa preocupação na bibliografia brasileira é quase absoluta, o diagnóstico não é muito melhor quando ampliamos nossos horizontes. Exceção feita a alguns notáveis nomes - Berdoulay, Livingstone, Buttimer; Robic, Capel, Claval, Stoddart, que são bastante conhecidos e citados, as outras oportunidades em que essas considerações se exprimem são marginais, desconhecidas e, muitas vezes, tomadas como uma curiosidade gratuita e sem importância. Além disso, em particular sobre

\footnotetext{
${ }^{1}$ A expressão quer dizer, em tradução livre: Depois disso, portanto, por causa disso. ESPAÇO E CULTURA, UERJ, RJ, JUL./DEZ DE 2020, N. 48, P. 35-55 http://www.e-publicacoes.uerj.br/index.php/espacoecultura/
} 
dinâmicas mais recentes ou contemporâneas, a ausência de trabalhos com essa abordagem é quase absoluta.

Contrasta com essa displicência o fato de que a comunidade de geógrafos se expandiu nos últimos 25 anos, sobretudo no Brasil. As grandes reuniões chegam a reunir algumas centenas de pessoas, tanto no Brasil quanto no exterior. Multiplicam-se as comissões temáticas que organizam simpósios e publicações. ${ }^{2}$ Orientações teóricometodológicas servem como fronteiras para definir grupos de pessoas que a elas se associam, ocupam cargos em instituições e estabelecem critérios de pertencimento e de ostracismo. Os principais veículos de divulgação, eventos científicos, publicações e nomeações para cargos são objeto de uma verdadeira guerra. Estratégias de todos os tipos são utilizadas para ganhar visibilidade e expressão. Como não considerar que todos esses elementos têm importância naquilo que é apresentado como sendo a Geografia?

Essa breve digressão pode levar o leitor à equivocada conclusão de que anseio apresentar um texto que ambicionaria preencher essa lacuna. Essa não é nem de longe a pretensão. Um trabalho que exiba com rigor e riqueza as circunstâncias do ambiente acadêmico e suas correlações com a produção do conhecimento demandará sempre um imenso esforço de pesquisa. Exigirá também uma exposição longa, com informações bem estruturadas e fundamentadas. Talvez justamente por isso, esse campo permaneça tão pouco frequentado.

Neste artigo, as ambições são bem mais modestas. A ideia surgiu com o próprio convite para participar de uma edição especial da revista Espaço e Cultura, comemorativa dos seus 25 anos. O prazo, portanto, foi exíguo e os meios para sua realização limitados. Desejei, no entanto, fazer algo adequado à ocasião. Deveria ter originalidade, que, segundo meu julgamento, foi a qualidade a mim oferecida nos regulares simpósios sobre Espaço e Cultura e em suas posteriores publicações. Por isso também, haveria de ser algo que pudesse conter um pouco da minha gratidão e respeito por essa história. Decidi refletir sobre as circunstâncias gestadas pelo grupo responsável por organizar os eventos e as publicações, o Núcleo de Estudos e Pesquisas sobre Espaço e Cultura (NEPEC), e como isso interferiu na minha própria produção intelectual durante esses anos.

Em resumo, trata-se de um exercício que contém preocupações próximas àquelas valorizadas pelos estudos de sociologia da ciência, mas mantém a esfera de reflexão restrita a um universo circunscrito e parcial. Em parte, esse exercício é similar ao que foi feito por Zeny Rosendahl em um artigo comemorativo aos 20 anos do NEPEC.

\footnotetext{
${ }^{2}$ Um exemplo recente foram os 55 Grupos de Trabalho na ENANPEGE de 2019. ESPAÇO E CULTURA, UERJ, RJ, JUL./DEZ DE 2020, N. 48, P. 35-55 http://www.e-publicacoes.uerj.br/index.php/espacoecultura/
} 
Nessa oportunidade, ela traçou o percurso do tema da religião nos estudos de Geografia cultural (ROSENDAHL, 2013). Eu escolhi comentar três contribuições minhas, apresentadas em edições do Simpósio Internacional sobre Espaço e Cultura e posteriormente publicadas na Revista Espaço Cultura ou na Coleção Geografia Cultural da Editora da Universidade do Estado do Rio de Janeiro (UERJ). Quero estabelecer a conexão que tiveram com o ambiente gerado por essas reuniões promovidas pelo NEPEC, coordenado por Rosendahl e sediado na UERJ. Gostaria, sobretudo, de ressaltar como alguns trabalhos meus, que reputo entre os mais criativos, talvez nunca tivessem existido sem a oportunidade por eles criada.

Eu participei desde o primeiro evento e fui, aliás, um dos mais assíduos palestrantes nas mesas-redondas dos encontros subsequentes. Lembro-me que no primeiro momento reagi à identidade dos meus trabalhos com a assim chamada Geografia Cultural. De fato, essa associação foi fruto de um acaso. Durante o doutorado, fiz parte do laboratório Géographie et Cultures (Université Sorbonne, Paris, França), coordenado por Paul Claval, meu orientador e um dos maiores expoentes, senão o maior, da Geografia Cultural naqueles anos. Fora a presença semanal nas reuniões desse laboratório e ter encontrado e discutido com geógrafos que, anos depois, se tornaram referências da Geografia Cultural, como Jöel Bonnemaison, Jean-Robert Pite, JeanFrançois Staszak, eu não via, em meu percurso intelectual, vínculos que pudessem me assentar com clareza dentro dessa orientação.

Ao voltar ao Brasil fui convidado por Roberto Lobato Corrêa para fazer uma apresentação no primeiro Simpósio sobre Espaço e Cultura. Ele havia sido meu professor no Mestrado, um grande incentivador de meu Doutorado na França e, desde minha entrada na UFRJ, em 1995, meu colega no Departamento de Geografia. Minha primeira reação ao convite foi a de procurar esclarecer, para mim mesmo, o que estávamos chamando de cultura e de que maneira eu poderia aproximar, ou não, minhas preocupações ao programa proposto pela Geografia cultural. O primeiro trabalho apresentado demonstra, aliás, essa ambivalência, expressa até em seu título: Identidade e exílio. Fundamentos para a compreensão da cultura (GOMES, 1998). Nos dois trabalhos apresentados ulteriormente, a questão ainda era a mesma e, ao final, acredito que a noção de cultura pública me foi útil no estabelecimento de um consistente elo temático (GOMES, 1999; GOMES, 2001). ${ }^{3}$

\footnotetext{
${ }^{3}$ Logo depois da apresentação, Denis Cosgrove (1948-2008) me disse que, curiosamente, havia feito o mesmo percurso antes de se associar à Geografia Cultural. Pensei que o percurso podia ser semelhante, mas o resultado foi um pouco diferente. Nunca concebi a Geografia Cultural como a sede teóricoESPAÇO E CULTURA, UERJ, RJ, JUL./DEZ DE 2020, N. 48, P. 35-55 http://www.e-publicacoes.uerj.br/index.php/espacoecultura/
} 
É preciso dizer que a geografia brasileira da época se apresentava dominantemente conformada aos estudos setoriais, acomodados nas tradicionais áreas de pesquisa: geografia física, geografia humana, regional, urbana, agrária, econômica e população. A novidade, quando existia, permanecia confinada a alguns temas da moda (geopolítica, globalização, fragmentação, espaciologia, entre outros). Nenhum assunto original tinha curso sem a anuência de que o tema proposto se encontrava em algumas dessas gavetas. Encontrar diálogo e atenção dependia assim da conformidade a um padrão que matava as possibilidades de transgressão com a sanção: “isto não é geografia”.

Ao final dos anos 1980, a densidade e o impacto dos trabalhos de Milton Santos, acompanhados do prestígio que ele já havia obtido fora do Brasil, abriu uma brecha na cápsula hermética das orientações teórico-metodológicas e temáticas na geografia brasileira. Entretanto, é necessário reconhecer que a originalidade das discussões trazidas por Santos rapidamente ficou, em parte, comprometida com os mecanismos da moda, ou seja, uma parcela significativa de geógrafos passou a segui-lo e a repeti-lo como apóstolos submissos.

Não à toa na Geografia costumamos nos referir às correntes do pensamento. Tal expressão revela, de alguma forma, esse entendimento de que todo o conhecimento deve se filiar a um grupo bem assentado de ideias. Como as ideias não circulam sozinhas, há sempre indivíduos que se associam a elas, as difundem e com elas se confundem. Como em uma seita, os membros têm seus deuses, são sectários e intransigentes com todos os outros que a eles não se submetem. Eles são servidores das ideias e, acorrentados a elas, almejam sucesso e prestígio e, se possível, estabelecer uma hegemonia acadêmica em torno delas.

Isso, mais uma vez, ocorreu com as ideias de Milton Santos. De fato, muitos queriam se associar ao prestígio e à ampla exposição propiciados por essa nova via e atacavam a Geografia tradicional, que anos antes praticavam e defendiam. É interessante sublinhar o procedimento condenatório que continuou a vigorar para estabelecer, a partir de princípios estreitos, apriorísticos e comprometido com grupos seletos, o que seria a boa geografia. Felizmente, não houve uma captura absoluta e as ideias trazidas por Milton Santos conseguiram romper com as estratégias de excomunhão, comuns nas dinâmicas da produção do conhecimento geográfico. Primeiro com timidez, depois de forma mais ampla, os autores ousaram sair das trilhas costumeiras, propuseram novos

metodológica dos meus trabalhos, mas encontrei muitos elos para justificar temas de uma geografia da cultura. 
temas e assuntos, novas abordagens e, aos poucos, libertaram o conteúdo geográfico do confinamento das tradicionais caixas temáticas.

Acredito que a emergência da Geografia Cultural entre nós deve ser pensada a partir desse contexto particular. Estudos variados que não encontravam garantia de reconhecimento, que não correspondiam aos tradicionais domínios da Geografia e que não dispunham de ambientes acadêmicos onde achariam interlocução, se abrigaram sob essa rubrica. Em contraposição, a mesma Geografia Cultural, para seus mais comprometidos defensores, era uma corrente, ou seja, continuava a ser concebida como um conjunto de geógrafos que partilhavam um horizonte consensual de precisas orientações teórico-metodológicas. Parece ser isso que alguns geógrafos caracterizam quando se referem ao giro cultural, expressão muito utilizada e que traduz um momento, ocorrido na última década do século XX, no qual teria se dado uma conscientização sobre a centralidade do elemento cultural na formação e na compreensão dos problemas geográficos (CORREA, 2003; CLAVAL, 2001). Aliás, isso fica bem caracterizado na distinção proposta de uma nova geografia cultural, em oposição à anterior. Tudo levaria a crer, portanto, que nessa nova manifestação haveria coerência, unidade e alinhamento de princípios, fundamentos e procedimentos. A Geografia Cultural significaria um movimento de transformação nos métodos e nos temas investigados.

Para todos aqueles que, por motivos diversos, não comungassem dessas orientações, o interesse em permanecer associados a ela, era o de obter a garantia de uma audiência, um círculo de interlocução e, sobretudo, o amparo de um rótulo que os permitiria existir na Geografia.

Por outro lado, os geógrafos afiliados à Geografia Cultural aceitavam a emergência de novos temas não necessariamente alinhados aos seus princípios estritos, pois isso os fortalecia como um movimento de peso e largo alcance. Criava-se, assim, uma massa crítica necessária para impressionar aqueles que de fora os contestavam.

Para além disso, houve também o efeito de moda, como chamamos atenção antes. Quando algo novo aparece, e dá a impressão de se transformar em um tema da atualidade, muitos se associam a ele em busca de prestígio e notoriedade. Isso já havia ocorrido inúmeras vezes e se repetiu com o movimento da Geografia Cultural no Brasil. Muitos colegas se recompuseram em geógrafos culturais sem apresentar, no entanto, nenhuma clara modificação em seus trabalhos ou concepções. Eles apenas acrescentaram esse rótulo e pretendiam, assim, estar em consonância com as últimas novidades do campo disciplinar. Estamos falando sobre o Brasil, mas o mesmo aconteceu no exterior. 
Uma boa medida do fenômeno pode ser observada se acompanharmos, por exemplo, a composição, ao longo dos anos, da comissão de Geografia Cultural da União Geográfica Internacional - UGI. No início, houve um momento de forte afluxo, com nomes bastante conhecidos e, nem sempre, muito claramente identificados com os temas da cultura. Depois, gradativamente, ocorreu um arrefecimento nessa inicial força de atração e, logo após, se seguiu uma aproximação com abordagens específicas, que antes não se apresentavam como culturais, mas viram a oportunidade para proceder a capturas institucionais e conquistar visibilidade, recursos e novos postos.

Defendemos, portanto, a ideia de que a Geografia Cultural viveu, e talvez ainda viva, uma forte tensão, fruto dos interesses diversos daqueles que reclamam o estatuto de seus legítimos representantes. Em síntese, há os que pretendem vê-la como um marco bastante claro de mudanças que conservam unidade temática e forte convergência teórico-metodológica. Há outros que aderem ao rótulo apenas para se beneficiarem dos efeitos associados à novidade. Finalmente, há aqueles que encontram nessa denominação uma brecha para divulgação de temas que não encontram oportunidade em outras áreas do conhecimento geográfico.

Apresentada dessa maneira, a Geografia Cultural escapa da retórica mítica que a vê como clara emergência de novos referenciais, coerentes e generalizados, e toma uma via bem mais incerta, como um movimento construído no cruzamento de caminhos que abrigam interesses diversos e espera resultados bastante diferentes.

Se o diagnóstico é verdadeiro, a organização de simpósios e publicações regulares deve ser a arena onde essas tensões mais fortemente se exercem. Os organizadores e editores são, por isso, talvez as maiores testemunhas dessas divergências de interesses. Por mais que tivessem uma ideia exata do que seria desejado, devem ter sido levados, em diversos momentos, a aceitar compromissos ou a suportar a aproximação com temas e colegas que julgavam distantes dos princípios que defendiam ou da compreensão que tinham sobre a identidade da Geografia Cultural. É legítimo, portanto, supor que os agentes responsáveis pela institucionalidade dessa orientação, os organizadores e editores do NEPEC, ainda que muito ciosos da preservação de suas marcas, também precisaram compreender, em variadas oportunidades, a importância de não se isolarem pela excessiva exclusão. Por isso também, entenderam o interesse que poderia existir em reduzir o controle do cursor da seletividade dos trabalhos a serem apresentados. 
Sem dúvida, dois personagens-chave nessa dinâmica são Zeny Rosendahl e Roberto Lobato Corrêa, pois grande parte do que apareceu nas publicações e nos simpósios passou por seus crivos. Não me permitiria fazer uma análise irresponsável fundada na psicologia de ambos. Não tenho competência e nem elementos para isso. Posso, no entanto, assegurar, como colega que sou dos dois, que houve alguns desconfortos surgidos na seleção de trabalhos e palestrantes. Muitos desses episódios foram causados pela estranheza das contribuições de alguns proponentes em face aos princípios que, para Rosendahl e Corrêa, deveriam estar presentes e serem respeitados. Isso se manifestou, por vezes, nos comentários ou perguntas subsequentes às apresentações nos simpósios. A importância desses momentos era lembrar a todos os rumos que deveriam ser seguidos na construção da Geografia Cultural. Havia, por isso, uma espécie de pedagogia que se construía pelos próprios comentários e apreciações. Da mesma forma, isso nos indica que, a despeito de toda a seleção feita nas proposições, nem tudo estava exatamente conforme aos preceitos da comissão organizadora. Tal constatação corrobora o que dissemos antes sobre a reunião de coisas muito diversas sob esse mesmo rótulo de Geografia Cultural.

A partir do desenho que foi traçado até aqui, eu posso situar melhor minha posição e a oportunidade dos meus trabalhos nesses simpósios e nas publicações a eles associadas. Antes de comentá-los, vale dizer que, desde os primórdios de minha carreira, nunca me senti à vontade nas estritas classificações temáticas praticadas na Geografia. Os assuntos para os quais se dirigia meu interesse não se acomodavam com perfeição, nem completamente, em nenhum deles. $\mathrm{O}$ primeiro projeto de pesquisa submetido às agências de financiamento, sobre cidadania e território, foi atacado, recebeu pareceres negativos, pois supostamente não correspondia às competências de um geógrafo. Inúmeras vezes ouvi reflexões de que aquilo sobre o qual eu falava não era Geografia.

O prestigiado geógrafo Antônio Christofoletti, depois de ler meu primeiro livro, Geografia e Modernidade, em 1996, me disse que havia apreciado muito, mas julgava que era a obra de um filósofo. O meu primeiro bolsista, ao apresentar o trabalho sobre a territorialidade das torcidas organizadas de futebol no Rio de Janeiro numa Jornada de Iniciação Científica, também em 1996, foi questionado com ironia sobre o interesse do tema para a Geografia e o avaliador continuou perguntando sobre a Geografia do basquete, da natação... e obteve a complacência geral demonstrada pelo riso da plateia. Inúmeras vezes fui questionado sobre a diferença do que eu estava pesquisando em relação à sociologia ou à antropologia. Quero dizer que, nos anos 1990, ainda prevalecia 
fortemente o apreço aos temas tradicionais e tudo aquilo que fugia dos recortes usuais era qualificado como relativo a outras áreas do conhecimento. A Geografia de então se dirigia a um conjunto muito restrito de tópicos e qualquer ousadia deveria ser punida com a exclusão. Essa atitude majoritária não me desencorajou a buscar novos temas. Ao contrário, permaneci obstinado a pesquisar a ocupação das praias, os arrastões, a metafísica aristotélica no pensamento de Vidal de La Blache, as contradições da democracia canadense, o papel do espaço nas composições imagéticas, entre outros tantos tópicos.

Sempre mantive a preocupação central de mostrar que o compromisso geográfico estava situado na forma como endereçamos perguntas a esses temas. Fiz dessa demonstração o elemento federador de todos esses assuntos. Por isso, sempre me senti confortável em buscar relações com campos não muito frequentados pela Geografia, como a filosofia do conhecimento, a história da arte, a antropologia, a filosofia política, o cinema, entre outros. Acredito que esses encontros sejam oportunidades enriquecedoras, pois entramos em contato com discussões novas sem nos perdemos dentro delas. Reafirmamos, assim, os limites de nossas competências e aptidões analíticas. Finalmente, encontrei na dinâmica dos espaços públicos uma riqueza que me proporcionou integrar alguns desses temas em uma linha de pesquisa, a qual me dedico desde então. Fui pioneiro nesse tema na Geografia e, apesar de atualmente a compreensão de sua importância não ser tão difícil de ser aceita, ainda são poucos os geógrafos que se dedicam a esse tema.

Nunca me interessaram os fenômenos da moda, aqueles que se apresentam nas conferências de abertura de grandes eventos ou ocupam grande número de pessoas em vários ambientes acadêmicos, todos repetindo a mesma coisa. Às vezes, me diverte constatar que há formulações utilizadas como uma espécie de código de apresentação. Ao se acionar certas expressões busca-se o conforto de dizer à audiência que estamos cumprindo o ritual da submissão aos temas que são eleitos como imperativos. Todos parecem ter que cumprir, em um momento ou outro, com esse cerimonial para produzir comunhão e aceitação. Tudo isso sempre me pareceu muito distante dos protocolos científicos desejáveis e eu nunca os segui. Evidentemente, meu desinteresse em participar dessas dinâmicas sempre me foi devolvido sob a forma de desatenção pelos temas que eu apresentava, manifestações claras de não pertencimento aos grupos que controlavam os temas tradicionais ou em moda e um isolamento ou distância que pode ser medido em metros, quando me encontro em algum desses grandes eventos. Rapidamente, no 


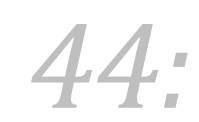

entanto, creio ter criado um lugar dentro da comunidade geográfica. A minha singularidade não desperta interesse, mas é aceita com relativa tolerância e sem grandes conflitos.

Dentro desse contexto, pode-se perceber a importância que a emergência da Geografia Cultural e os simpósios organizados pelo NEPEC tiveram para mim. Por um lado, pude me abrigar na pluralidade de temas que a abordagem cultural acolhe, sem a necessidade de me filiar ao programa de pesquisas proposto por ela. Em nenhum momento me apresentei como geógrafo cultural, nem isso me foi demandado, embora fosse convidado em quase toda a série de eventos e nas principais publicações do NEPEC. Por outro lado, consegui obter a atenção de uma audiência aberta e a boa aceitação dos trabalhos apresentados foi um elemento decisivo no estímulo à produção de novo material para esses eventos.

O auditório continuamente cheio, os comentários positivos sobre as apresentações, o entusiasmo e incentivo, sempre presentes, de Zeny Rosendahl e de Roberto Lobato Corrêa, outros colegas presentes nas reuniões interessados e interessantes, foram esses os ingredientes que me estimularam a fazer um crescente investimento para retribuir com meu melhor possível nessas oportunidades. Com muita antecedência começava a conceber os temas passíveis de serem discutidos. Tinham que ser inéditos e deviam causar certo impacto pela originalidade. Era necessário, igualmente, que fossem muito bem trabalhados, ou seja, objetos de uma verdadeira pesquisa. A ousadia criativa não pode ser irresponsável, sob pena de ser confundida com leviandade. Isso gerava então um forte comprometimento com o levantamento e a análise bibliográfica. Como os temas eram novos, havia pouco material já reunido por outros pesquisadores.

Além disso, os assuntos se situavam no encontro de muitas áreas do conhecimento, não corriqueiramente frequentadas por geógrafos e, por isso, tinha que compensar minha ignorância com uma farta carga de leitura. O resultado foi uma expansão formidável do tipo de informação e dos debates que tinha que percorrer. Como em uma caçada, não escolhemos de antemão o percurso e nem sempre conhecemos o terreno sobre os quais somos levados a nos dirigir na sequência da perseguição da presa. Aprendi muita coisa nova sem que isso fizesse parte de um programa pré-estabelecido. Fui surpreendido e desenvolvi novos interesses a partir dessas experiências. Aos poucos aprendi que, sem me desviar da minha condição de geógrafo, poderia me deslocar por 
insuspeitos debates e reflexões e encontrar sentido em uma bibliografia a princípio bastante estranha ao campo das preocupações geográficas.

Tudo isso pode parecer muito programático e pouco amparado em demonstrações. Por isso, escolhi três de meus trabalhos que, espero, exemplificam com exatidão o que foi exposto.

\section{Os exemplos}

O primeiro talvez esteja entre os meus trabalhos mais conhecidos para quem acompanhou de perto esses eventos: Versalhes não tem banheiros! (GOMES, [2005] 2008) Nele, parto da ideia de que a mudança de mentalidade que assistiu a eclosão de um novo hábito e valor social, a intimidade, no século XVIII, foi acompanhado por uma reorganização dos espaços urbanos. No interior das residências, houve a criação de banheiros e uma nova disposição dos cômodos e da circulação entre eles. A intimidade, para ser vivida, demandava espaços apropriados. No âmbito da cidade, as mudanças geraram a demanda por equipamentos de infraestrutura responsável por grandes reformas urbanas, redes de abastecimento de água, redes de esgoto, reservatórios, castelos d'água etc. A chegada da água às casas dependia da pressão gravitacional e, no começo da implantação dos sistemas de abastecimento, se desenvolveu uma valorização incomum dos andares inferiores dos edifícios, já que eles recebiam com exclusividade os pontos de chegada da água.

De forma geral, é possível pensar que a distinção entre espaços públicos e privados, que, há algum tempo, já caracterizava a organização espacial urbana e criava o quadro de referência fundamental das relações sociais, se viu acrescida de uma nova esfera, a íntima. O banheiro, um tipo de delimitação espacial de equipamentos e um lugar assignado para certas ações e atitudes, é um dos mais claros sinais dessa mudança. A organização espacial nos revela, com sutileza, mas de forma enfática, a necessidade de pensar os valores e atitudes sociais em sua relação com a forma física que os condiciona, os enquadra, os caracteriza e os exibe, ou seja, os tornam concretamente visíveis.

Tentei também analisar em tal pesquisa o quanto esses hábitos são dependentes do desenho espacial para existir. O resultado confirmou a relação dialética entre espaços físicos e comportamentos já encontrada recorrentemente em diversas outras pesquisas. Parafraseando Vidal de La Blache, ao observar o comportamento humano no espaço, vemos que ele é simultaneamente ativo e passivo e não conseguimos determinar até que 
ponto ele é um ou outro ${ }^{4}$. O que acaba de ser dito indica o quanto um estudo de caso, aparentemente curioso e anedótico, pode conter de matéria essencial para discussões teóricas que não necessariamente devem prescindir de recursos empíricos para se constituírem - talvez recomendem exatamente o contrário.

O caso do Castelo de Versalhes me pareceu interessante, pois ele foi construído (1669-1678) com os recursos mais atualizados da época. Ele possuía sistemas hidráulicos sofisticados para fazer funcionar suas inúmeras fontes, canais e chafarizes, tinha aproximadamente 700 cômodos, mas não dispunha de nenhum banheiro. Em meados do século seguinte, já no reinado de Luís XV, reformas sucessivas nos cômodos começaram a ser feitas para dar ensejo a um novo conjunto de atitudes, então reconhecidas como essenciais: recolhimento, isolamento e abrigo em relação aos olhares alheios. Na realeza, surge a vontade inédita de estabelecer uma fronteira entre a vida pessoal e o papel da representação formal. É a compreensão da individualidade que está em transformação. As relações do indivíduo com o corpo e com a intimidade adquirem novos contornos. A criação de banheiros, que é um tipo de espaço, só pode ser compreendida nesse contexto. Se isso se manifesta na aristocracia francesa de meados do século XVIII, não significa que seja um fato isolado e exclusivo. Ao que tudo indica, as primeiras demandas dessas transformações físicas do castelo de Versalhes foram trazidas pela Madame de Pompadour, amante de Luís XV, que era oriunda de uma família burguesa. Aliás, os primeiros banheiros da época apareceram nas casas dessas famílias. Tudo isso corrobora a tese do surgimento de uma esfera burguesa que redesenhou o individualismo moderno, tese presente em obras seminais de autores como Habermas (1994 [1962]), Elias (1990) e Dumont (1992). Tantas relações importantes podem ser estabelecidas com um assunto aparentemente tão menor: a criação moderna dos banheiros! Essa foi a ideia básica do texto e de sua apresentação no simpósio Espaço e Cultura de 2004.

O segundo exemplo teve origem em um programa de pesquisas realizado no Canadá, em 1996 e 2002. Em 1995, houve uma consulta plebiscitária no Quebec para decidir se essa província continuaria ou não na federação canadense. O movimento separatista do Quebec era, então, intenso e despertava fortes reações daqueles que a isso eram contrários, os federalistas. Um dos argumentos mais evocado pelos defensores da separação era a queixa de que a cultura de origem francesa, majoritária no Quebec, vinha sendo sistematicamente suprimida pela comunidade de origem ou de afinidade

\footnotetext{
${ }^{4}$ A frase original de Vidal de La Blache é a seguinte: "O Homem faz parte dessa cadeia e, em suas relações com o que o cerca, ele é ao mesmo tempo passivo e ativo, sem que seja possível determinar na maioria dos casos até que ponto ele é um ou outro” (VIDAL DE LA BLACHE, 1921, p.104. Tradução do autor). 
anglofônica. A pesquisa discutia o papel da identidade territorial e de sua mobilização no movimento regionalista quebequense no contexto multiculturalista, que é um dos fundamentos constitucionais da federação canadense. Em termos mais gerais, o programa de pesquisa discutiu a complexa relação entre democracia e espaço e, evidentemente, isso também interrogava as relações entre cultura e território.

Durante minha estadia, eu fiz observações sobre a maneira como nos habituávamos rapidamente a identificar os terrenos de cada um dos campos que se opunham. Sabíamos se deveríamos nos dirigir às pessoas dizendo Hi ou Salut, e isso condicionava a facilidade ou dificuldade do contato social, em ambientes institucionais, comerciais ou na esfera das relações privadas. Interessei-me, sobretudo, pela sutil sinalética espacial que funcionava com eficiência, sem que muitas vezes eu pudesse ter certeza de que era plenamente consciente para os próprios canadenses. O fato é que um repertório de qualidades e atributos espaciais servia de guia para classificar as áreas segundo a distinção básica entre francófonos e anglófonos: materiais, cores, formatos, localizações, posições, tipos de equipamentos etc. Era como se o mundo material segue a mesma e fundamental distinção que se ativara com os anseios separatistas e dividia as pessoas nessa parte do país.

Muito embora o tema central da pesquisa não fosse esse, observei alguns elementos espaciais que nos orientavam nesse mundo dividido. A província de Ontário, vizinha ao Quebec, de predomínio de população anglófona, possui também forte presença de francófonos. As áreas do extremo sudoeste exibem um povoamento como um tabuleiro de xadrez, localidades de origem anglófona se alternam com francófonas. Por isso escolhi localidades vizinhas para sistematizar as observações. O próprio desenho urbano revela sua origem. Cidades de povoamento francês são lineares e crescem ao longo de um eixo, com poucas ruas secundárias. O centro conta com uma praça, muitas vezes a única, e nela há uma imponente igreja católica. A testada dos lotes é estreita e quase toda ocupada pela edificação das residências. Tudo isso corresponde com perfeição ao já descrito sistema de rangs, usado no período de colonização francesa (DEFFONTAINES, 1953; BLANCHARD, 1960).

Em contrapartida, as cidades de origem anglo-saxã têm ruas ortogonais e modelo nucleado. A centralidade é marcada pela presença da prefeitura (City Hall), algumas vezes também pelas escolas secundárias e as igrejas e templos não estão localizados no centro. A implantação das casas no lote nunca é na testada, as fachadas, em geral, são laterais e sempre há gramados e vegetação à volta, com relativa indistinção 
dos limites entre os lotes, característica que se torna mais intensa à medida que nos afastamos do centro. No que diz respeito aos materiais de construção, a duplicidade dos modelos se mantém: casas de tábuas de madeira horizontais, para os franceses, contrastam com tijolos e madeirame branco, para os anglo-saxões. O mesmo pode ser dito dos jardins, públicos e privados, e até para a seleção das plantas! A dualidade continua válida para o comércio, para o mobiliário urbano, para a palheta cromática das edificações, entre outros elementos visíveis no espaço.

Uma observação mais acurada, no entanto, pode revelar algumas falhas nessa perfeita dualidade - ressaltada e valorizada por todos os entrevistados, e que se expõe com naturalidade aos olhos de todos. Percebemos, por exemplo, que as origens dos sobrenomes nem sempre correspondem aos modelos construtivos das habitações, sobretudo nas confortáveis casas em centro de terreno, presumidamente ocupadas por famílias de origem anglo-saxã. Igualmente, nas casas mais simples de madeira, onde deveriam habitar famílias de origem francesa, há, muitas vezes, pessoas de baixa renda de origem étnica diversa. O forte contingente de descendentes de irlandeses, como os franceses, marcados pelo catolicismo e pelo antagonismo em relação aos ingleses, mas anglófonos, é também outro ingrediente que não se coaduna com a perfeição das oposições.

O mais importante, no entanto, é que no interior das casas, no estilo de vida da população, nos hábitos de consumo e até mesmo no plano dos cômodos das residências, há uma estreita similaridade que foge inteiramente dessa dualidade. As distinções apresentadas são, em certa medida, uma mise-en-scène. Essa forma de apresentar a cultura material alinhada e derivada das duas matrizes, francesa e inglesa, é uma narrativa para sublinhar um combate territorial entre comunidades. O efeito de fachada dessa narrativa se assemelha perfeitamente ao que descreveu Erving Goffman sobre o comportamento dos indivíduos, orientado por delimitações espaciais básicas: fachadas e coxias (GOFFMAN, 1959). Nas interações sociais há estratégias que buscam causar impressões e transmitir mensagens, e, tal qual ele, poderíamos nos perguntar até que ponto as pessoas acreditam nesses estereótipos e se projetam neles e até onde essas ações e apresentações são ações calculadas para produzir determinados efeitos. Culturas estéticas são também sistemas de ações políticas. A teoria sociológica das interações sociais pode ser útil para investigarmos paisagens e, com sua ajuda, aprendemos que as expressões espaciais da cultura não são sempre de compreensão imediata e simples. Na apresentação do trabalho no Simpósio de 2002 mantive, na maior parte do tempo, a 


\section{9:}

dualidade como uma explicação coerente e suficiente e, ao fim, apresentei sua desconstrução. Quis criar o incômodo da mudança explicativa brusca e deixar como mensagem final o desconforto da dúvida.

Finalmente, o terceiro exemplo que quero trazer teve origem em uma apresentação no Simpósio NEPEC 20 anos, em 2013, e depois se transformou em capítulo de um livro em homenagem a Paul Claval. O tema se desenvolve a partir de um lugar: o Jardin des Plantes de Paris. Originalmente criado como um domínio real para aclimatação e estudo de espécies vegetais trazidas de diferentes partes do mundo, esse jardim rapidamente se transformou em uma instituição de pesquisa de primeira linha para diferentes áreas do conhecimento das ciências naturais (biologia, zoologia, geologia). Nessa instituição atuaram personagens mundialmente conhecidos, tais como: Antoine e Bernard de Jussieu, Buffon, Lamarck, Daubenton, Geoffroy de Saint-Hilaire, Cuvier, entre outros. De certa forma, a história da biologia entre os séculos XVIII e XIX pode ser em grande parte contada a partir dessa instituição e de seus personagens.

O arranjo físico do Jardim foi também se modificando ao longo dos anos. Novas parcelas foram anexadas e as disposições físico-espaciais foram se diferenciando, redefinindo os acessos, os limites e a circulação. Alamedas retilíneas, com plantas alinhadas geometricamente, foram justapostas às trilhas sinuosas, labirínticas, com elementos pitorescos ou ainda largas áreas gramadas, com grandes árvores esparsas. Podemos, sem dificuldade, identificar parcelas comprometidas com os modelos dos jardins ditos à francesa, à inglesa, jardim romântico, jardim barroco, jardim renascentista, jardim oriental etc. Além desses elementos, o Jardin des Plantes também conta com numerosos equipamentos espalhados em seu terreno: a galeria da evolução, os pavilhões da botânica, da zoologia, da mineralogia, os pequenos zoológicos, os canteiros com função pedagógica, o museu, a biblioteca, as estufas das plantas tropicais, os herbários e outras pequenas estruturas. Ao longo dos anos, o espaço do Jardim foi ganhando diferentes marcos que contam sua história ou homenageiam seus mais ilustres personagens. Placas, colunas, monumentos e, sobretudo, numerosas esculturas se distribuem sobre toda sua extensão. A pergunta que deu origem ao trabalho foi aquela que se interroga sobre a distribuição espacial desses conjuntos de elementos: formas e desenho dos jardins; os equipamentos que deles fazem parte; e os marcos e memoriais de homenagem. Haveria algum tipo de relação na distribuição entre eles? Sua organização espacial guarda uma lógica interna? Que elemento poderia ter presidido a escolha de 
suas localizações? Em outras palavras, há algum tipo de narrativa que pode ser lida a parir da disposição física desses elementos?

Havia uma pista importante a seguir. Colocar placas comemorativas, memoriais e esculturas de personagens espalhados tem como função primordial rememorar eventos e pessoas. O primeiro passo importante da pesquisa foi, por isso, colocar minuciosamente esses elementos em um mapa. Se a pista fosse correta, o mapa poderia dar acesso a uma leitura que apareceria na coerência da distribuição espacial dessas diferentes peças. Tal qual um quebra-cabeças, seria preciso proceder por aproximações para entender como cada uma das peças encontra seu lugar nesse emaranhado. Restava, no entanto, um problema central: qual seria o cimento dessa narrativa? A própria história da biologia. Nada mais lógico que os arranjos espaciais e a maneira de distribuir imagens comemorativas dos personagens exprimissem a compreensão do papel atribuído a eles e às suas realizações. Querelas, oposições, visões gerais sobre a natureza, domínios que se associam aos personagens, deveriam se revelar nessas escolhas posicionais dentro do jardim. A própria figuração exposta na escultura (posição, proximidade, animais e plantas associados etc.) deveria conter os indícios dessa narrativa global.

O desafio para mim foi o de reunir material que pudesse me informar sobre as etapas da organização do espaço nessa instituição e, sobretudo, conhecer, pelo menos de forma geral, a história da biologia desse período. Como disse antes, não sabemos exatamente os caminhos que teremos que percorrer quando começamos uma pesquisa e muitas vezes somos levados a trilhas nunca imaginadas. Em contrapartida, saímos sempre com uma bagagem de conhecimento renovada e com a sensação de que aquele conhecimento adquirido foi a chave para respondermos a uma questão geográfica. Não há gratuidade nessa erudição, ela responde a uma necessidade bastante objetiva. Nessa empreitada, contei com pessoas da instituição que me ajudaram a reunir as informações e, muitas vezes, contaram histórias que me auxiliaram no estabelecimento do fio da narrativa espacial. Isso confirmou que a coerência que eu buscava não era apenas um elemento artificial, fabricado pelo meu empenho em ver uma geografia (uma ordem espacial) de qualquer forma, em qualquer lugar (COSGROVE, 1989). A narrativa espacial existia de fato, mesmo para pessoas que nada tinham a ver com a Geografia.

Munido desse material e do entusiasmo pelos rumos que o trabalho tomou, eu pensei que não poderia simplesmente apresentá-lo no simpósio como uma enfadonha sequência de slides. Antes, já havia nas apresentações, tanto do Versalhes não tem banheiros, assim como no do exemplo canadense, procurado inovar na comunicação ao 
utilizar alternativas às cansativas rotinas que dominam esse tipo de ritual acadêmico. Os resultados dessas experiências foram muito satisfatórios. As pessoas lembravam das apresentações e pareciam apreciar os novos formatos. Decidi então apresentar o conteúdo dessa pesquisa sobre o Jardin des Plantes como um jogo, um jogo de posições. Desenhei o mapa pictórico do jardim como um tabuleiro, escolhi algumas esculturas e as descrevi. Contei a história dos personagens e dos enredos que os ligam à história da biologia e, depois, pedi para que as pessoas no auditório associassem os lugares deixados vazios no tabuleiro aos personagens, seguindo as pistas da coerência entre seus feitos e a localização no arranjo posicional dentro do espaço do jardim. Produzi uma grade, com escores que variavam entre excelente e fraco raciocínio geográfico, segundo o índice de acertos e erros das pessoas às perguntas.

A pesquisa e a apresentação foram dedicadas ao meu orientador de doutorado, Paul Claval. Nos dias em que tínhamos aulas com ele, eu atravessava as alamedas do Jardim no caminho entre a minha casa e a Universidade. Durante minha estadia na França, muitas vezes pensei que não conseguiria dominar o conjunto de informações e referências trazidas pelas aulas e seminários. Elas se renovavam a cada dia e pareciam ser inesgotáveis. Saia das aulas e ia direto para a biblioteca com os nomes dos autores e as citações das obras para, pelo menos, ter uma ideia do tamanho da minha ignorância. Alguns dos personagens fixados nas esculturas do Jardin des Plantes faziam parte dessas lacunas que aos poucos fui preenchendo. Claval sempre foi para mim um exemplo de erudição e, por isso, achei que ele gostaria da apresentação e da ousadia de apresentar o tema sob a forma de um jogo. Sem muita surpresa, ele acertou todas as respostas e fez comentários muito positivos.

O trabalho foi publicado no livro em homenagem a ele, organizado por uma rede de pesquisadores da Geografia Cultural, de certa forma concorrente ao NEPEC (NABOZNY, 2014). Esse grupo de pesquisadores do Núcleo de Estudos em Espaço e Representações - NEER, também se apresenta como uma rede de pesquisadores próximos da abordagem cultural na Geografia, abertos aos novos temas. A diferença é sutilmente denotada pela afirmação de que se trata de uma rede não formal, não hierarquizada, de caráter interinstitucional ${ }^{5}$. A escolha da denominação Rede fornece também uma pista sobre as alegadas diferenças: menor grau de centralização e menor hierarquia interna entre os componentes (HEIDRICH, COSTA e PIRES, 2013). Muito embora possa haver significativas diferenças na estrutura desses dois grupos, eles

\footnotetext{
${ }^{5}$ Disponível em: http://www.neer.com.br/home/?page_id=24. Acesso: 12 de outubro de 2020. ESPAÇO E CULTURA, UERJ, RJ, JUL./DEZ DE 2020, N. 48, P. 35-55 http://www.e-publicacoes.uerj.br/index.php/espacoecultura/
} 
parecem manter a mesma obrigação de acolher grande variedade de temas e, assim, preservar o espírito que prevaleceu na manifestação da Geografia Cultural. A questão para ambos os grupos é saber se essa abertura será ou não mantida ou se, em algum momento, não serão cooptados por uma tendência ou corrente majoritária.

\section{Inquietações}

Cumpre dizer que a dinâmica pela qual se cria a sensação de mudança na Geografia ainda é, nesses últimos 30 anos, em sua maior parcela, a mesma identificada como o mito da modernidade geográfica (GOMES, 1996). Esse mito se nutre repetidamente da mesma estrutura que estabelece um suposto oponente que deverá ser então superado por uma nova e melhor orientação (corrente). Todo o esforço consiste, pois, a sublinhar as diferenças e a convencer que uma nova etapa, mais apropriada, mais ajustada e mais competente, enfim, uma melhor abordagem, está surgindo e se impondo sobre tudo aquilo que existia. A denominação desses movimentos não esconde essa dinâmica, já que, em geral, explicitamente se denominam de forma a caracterizar a suposta ruptura com o que veio antes - nova e pós são, assim, comumente utilizados para anteceder as denominações (nova geografia cultural, pós-moderna, pós-estruturalista, pós-colonial, decolonialidade) Assim o fazendo, elas se associam de imediato à ideia de oposição e superação.

É inegável que cada uma dessas orientações procura trazer novos temas ou preocupações, mas a ênfase quase nunca se concentra na produção do conhecimento, no desenvolvimento de pesquisas ou em posições derivadas delas. Os trabalhos se apresentam como manifestos, como tomadas de posição, e os temas são, em geral, secundários em face da exibição de posturas gerais e programáticas. Consideradas em conjunto, essas manifestações produzem um efeito de movimento a partir de uma sucessão de tendências reagrupadas em rótulos, em marcas. Como em um banal mercado, o que parece importar mais é o valor simbólico de uma marca, e não propriamente o conteúdo que ela encerra. As novidades sempre se anunciam superiores em desempenho, em responsabilidade, em capacidade de trazer resultados melhores. Essa é a tônica dos discursos.

Nas comuns histórias da geografia quase nunca o fio narrativo se associa ao desenvolvimento de um tema. O que acrescentamos ao conhecimento que tínhamos sobre algo? Como isso foi produzido? Que pesquisas foram feitas? Que compreensões 
originais foram produzidas? Que novos instrumentos teórico-metodológicos foram mobilizados?

Nessa ansiogênica dinâmica não há reconhecimento para os trabalhos que não se dispõem a seguir o receituário das necessárias novidades. Procuramos argumentar aqui que o aparecimento da Geografia Cultural, nas condições particulares em que foi desenvolvida e promovida pelo NEPEC, significou uma quebra nesse padrão. Atribuímos isso não à personalidade do grupo de pessoas e de seus interlocutores, nem ao lugar onde se passou, nem propriamente ao momento em que se constituiu, mas, sem dúvida, esses elementos, em conjunto, colaboraram para o surgimento das circunstâncias favoráveis à inovação temática e teórico-metodológica da Geografia.

O fato é que nos três trabalhos retomados aqui não há resquício de comprometimento ou filiação a qualquer corrente ou abordagem específica, nem com uma suposta orientação que caracterizaria a Geografia Cultural. O compromisso fundamental é com o raciocínio geográfico, com uma explicação que busca sentido na ordem espacial dos fenômenos. As referências bibliográficas não fazem concessão aos autores da moda e seguem como padrão apenas a pertinência com o tema ou com a explicação buscada. Os assuntos, no entanto, são novos no temário clássico da Geografia e os percursos explicativos inéditos.

A apresentação dos trabalhos foi aqui bem rápida, sem todos os ingredientes e desdobramentos que possuem, pois, o objetivo foi apenas o de ressaltar a especificidade que cada um deles eventualmente carrega. Em comum, eles têm o esforço de associar livremente esses variados casos às discussões teóricas pertinentes, estabelecidas ao sabor do que me apareceu como possibilidade explicativa. As escolhas teórico-metodológicas não foram feitas de antemão. Não são manifestos em favor de uma especificidade associada a uma escola de pensamento. Não precisei de uma teoria da cultura para fazer os trabalhos, sequer necessitei de uma justificativa para colocá-los em um Simpósio de Geografia Cultural.

Os exemplos trazidos têm evidentes relações com a cultura, mas poderiam também ser vistos como estudos de geografia urbana, geografia política, geografia histórica. Apraz-me pensá-los como Geografia, simplesmente! Como nos disse Claval (2007), toda Geografia é cultural, e essa denominação significa somente a abertura do campo para temas antes desprezados pela maior parte dos geógrafos.

Isso significa uma Geografia que não se esgota nos terrenos de sua tradição, que, ao contrário, procura novas relações, novos assuntos, que aplica um raciocínio 
espacial a temas que assim nunca foram pensados e, por isso, colhe resultados inéditos. Pode ser que essa seja uma via para encontrar a relevância e o tão demandado reconhecimento que, muitas vezes, nos é sonegado por nossos pares de outros campos do saber. Pode ser que isso nos proteja um pouco da moda e dos comportamentos de matilha, que faz com muitos sigam uma só direção, encalçando um mesmo e único objetivo. Pode ser que isso nos liberte dos programas e temas pré-estabelecidos e dos rituais sectários que condenam e conformam toda a curiosidade a um exclusivo mirante. Pode ser também que não seja nada disso.

De qualquer maneira, o que tenho certeza é que esses trabalhos foram gerados por uma espontânea inspiração e fundados em um livre arbítrio. Para isso precisei contar com um espaço de liberdade e criatividade que me foi proporcionado pelo contex to criado pelo NEPEC, por seus coordenadores e integrantes, pelos eventos que organizaram, pelas publicações que realizaram. Sem isso, também tenho certeza de que esses trabalhos talvez nunca tivessem existido. Espero que a Geografia Cultural, ou qualquer outro rótulo que venha a se justapor à Geografia, como a que foi até aqui praticada pelo NEPEC, continue seguindo o mesmo rumo. Que seja um abrigo para a originalidade e ousadia, um lugar que permita experiências novas e, sobretudo, que não se vergue aos ditames da moda e não se deixe seduzir pela ortodoxia.

\section{REFERÊNCIAS BIBLIOGRÁFICAS}

BLANCHARD, Raoul de. La Canada français, province du Quebec, étude géographique, Fayard, Montreal, 1960.

CLAVAL, Paul. O papel da Nova Geografia Cultural na compreensão da ação humana. In: Rosendahl, Z. e Corrêa R. (org.) Matrizes da Geografia Cultural. EDUERJ, Rio de Janeiro, 2001.

CLAVAL, Paul. Geografia Cultural, Ed UFSC, Florianópolis, 2007.

CORREAA, R. e ROSENDAHL, Z. (org.). Introdução á Geografia Cultural, Bertrand Brasil, Rio de Janeiro, 2003.

COSGROVE, D. "Geography is Everywhere: Culture and Symbolism in Human Landscapes". Horizons in Human Geography, D. GREGORY et al (eds.). Palgrave, London, 1989.

DEFFONTAINES, Pierre. «Le rang, type de peupleument rural du Canada français ». Le Cahiers de Géographie, Université de Laval, nº 5, pp. 3-30, 1953.

DUMONT, L. Ensaios sobre o Individualismo. Uma perspectiva antropológica sobre a ideologia moderna, Dom Quixote, São Paulo, 1992.

ELIAS, N. O processo civilizador: Uma história dos costumes, Zahar, Rio de Janeiro, 1990. 
GOFFMAN, Ervin. The presentation of Self in Everyday Life, Doubleday, New York, 1959.

GOMES, P. C. da Costa. Geografia e modernidade. Bertrand Brasil, Rio de Janeiro, 1996.

GOMES, P. C. da Costa. "Identidade e exílio: fundamentos para a compreensão da cultura". Espaço e Cultura, Rio de Janeiro, n.5, p. 31-42, 1998.

GOMES, P. C. da Costa. "Cultura ou civilização: a renovação de um importante debate". In: Z. Rosendahl \& R.L. Corrêa, dir., Manifestações da cultura no espaço, Ed. UERJ, Rio de Janeiro, 1999.

GOMES, P. C. da Costa. "A cultura pública e o espaço: desafios metodológicos". In: Z Rosendahl \& R. L. Corrêa, (dir.) Religião, Identidade e Território, EDUERJ, Rio de Janeiro, pp. 93-113, 2001.

GOMES, P. C. da Costa. "A paisagem urbana como cenário de uma cultura: Algumas observações a propósito do Canadá”. Espaço e Cultura, no 17, pp. 7-15, 2004.

GOMES, P. C. da Costa. "Versalhes não tem banheiros. As vocações da geografia cultural". Espaço e Cultura, ed. Comemorativa, v. 1, pp. 175-183, 2008.

GOMES, P. C. da Costa. "Naturalistas no jardim. Sobre o poder pedagógico e comunicacional do espaço”, É geografia, é Paul Claval, SILVA, B. J.; ALMEIDA, M. G.; ARRAIS, T. A. (org), FUNAPE), Goiânia, 2013.

HABERMAS, J. The Structural Transformation of the Public Sphere, Polity Press, Cambridge, [1962] (1994).

HEIDRICH, Álvaro L.; COSTA, Benhur P. da; PIRES, Claudia L. Z. Maneiras de ler: geografia e cultura. Compasso Lugar-Cultura, Porto Alegre, 2013.

KUHN, Thomas. A estrutura das revoluções científicas. Perspectiva, São Paulo, 1983.

MONTEIRO, Carlos Augusto de F. "Travessia da crise (Tendências Atuais na Geografia)", Revista Brasileira de Geografia, Rio de Janeiro, ano 50, nº especial, t.2, pp. 100-127, 1988.

NABOZNY, Almir. Abordagens culturais na geografia brasileira. Uma compreensão. Tese de Doutorado, PPG-IGEO-UFRGS, Porto Alegre, 2014.

ROSENDAHL, Zeny. "Lugar onde se pensam as ideias e se escreve sobre elas. MemóriasHistória do NEPEC 1993-2013" Espaço e Cultura, n XX, pp. 1-14, 2013.

ROSENDAHL, Z. Espaço e religião: Uma abordagem Geográfica. EDUERJ, Rio de Janeiro, 1996.

ROSENDAHL, Z. Hierópolis: O sagrado e o urbano. EDUERJ, Rio de Janeiro, 1999.

ROSENDAHL, Zeny e CORREAA, Roberto Lobato (org.) Religião, identidade e território, Rio de Janeiro, Ed. UERJ, pp. 93-114, 2001.

VIDAL DE LA BLACHE, Paul (1921) Principes de géogaphie humaine, Armand Colin, Paris, 1921. 